\title{
Observed surface wind speed in the Tibetan Plateau since 1980 and its physical causes
}

Qinglong You ${ }^{1,2 *}$, Klaus Fraedrich ${ }^{2}$, Jinzhong Min ${ }^{1}$, Shichang Kang ${ }^{3,4}$,

Xiuhua Zhu ${ }^{2}$, Nick Pepin ${ }^{5}$, Ling Zhang ${ }^{1}$

1. Key Laboratory of Meteorological Disaster, Ministry of Education, Nanjing University of Information Science and Technology, Nanjing, 210044, China;

2. Max Plank Institute for Meteorology, KlimaCampus, Hamburg 20144, Germany;

3. State Key Laboratory of Cryospheric Science, Chinese Academy of Sciences (CAS), Lanzhou 730000, China;

4. Laboratory of Tibetan Environment Changes and Land Surface Processes, Institute of Tibetan Plateau Research, CAS, Beijing 100085, China;

5. Department of Geography, University of Portsmouth, U.K. (14)

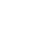

* Corresponding author E-mail address: yqingl@ 126.com

Resubmitted to International Journal of Climatology, July 5, 2013

8


Abstracts: Climate warming on the Tibetan Plateau (TP) potentially influences many climate parameters other than temperature including wind speed, cloudiness and precipitation. Temporal trends of surface wind speed at 71 stations above $2000 \mathrm{~m}$ above sea level in the TP are examined during 1980-2005. To uncover causes of observed trends in wind speed, relationships with surface temperature, a TP index and sunshine duration are also analyzed. The TP index is calculated as the accumulated $500 \mathrm{hPa}$ geopotential height above $5000 \mathrm{~m}$ over the region of $30^{\circ} \mathrm{N}-40^{\circ} \mathrm{N}$, $75^{\circ} \mathrm{E}-105^{\circ} \mathrm{E}$ from NCEP/NCAR reanalysis. The annual mean wind speed patterns during 1980-2005 are similar to those in different seasons, with higher wind speeds in the northern and western parts of the TP. Highest mean wind speeds occur in spring and lowest in autumn. During 1980-2005, annual and seasonal mean wind speeds show statistically decreasing trends at most stations. The mean trend magnitude for annual mean wind speed is $-0.24 \mathrm{~m} / \mathrm{s} / \mathrm{decade}$, with the maximum decline in spring $(-0.29 \mathrm{~m} / \mathrm{s} /$ decade $)$ and minimum in autumn $(-0.19 \mathrm{~m} / \mathrm{s} /$ decade $)$. Both annually and in different seasons, wind speed is significantly negatively correlated with mean temperature, minimum temperature, maximum temperature, and the TP index, but significantly positively correlated with sunshine duration. Wind speed trends fail to show a simple elevation dependency but speeds are positively correlated with meridional surface temperature/pressure gradients. Warming in the TP may weaken the latitudinal gradients of both regional temperature and surface pressure, thus altering the regional atmospheric circulation and accounting in part for the observed decline of wind speed.

Key words: Tibetan Plateau; wind speed; Tibetan Plateau index; Mann-Kendall analysis 


\section{Introduction}

According to the Intergovernmental Panel on Climate Change (IPCC) Fourth Assessment Report (AR4), global mean surface temperature has risen by $0.74 \pm 0.18^{\circ} \mathrm{C}$ during the last 100 years (1906-2005), and the rate of warming over the last 50 years is almost $0.13{ }^{\circ} \mathrm{C} / \mathrm{decade}$ (IPCC, 2007). Future warming is estimated over the next 20 years to be a rate of $0.2{ }^{\circ} \mathrm{C} /$ decade (IPCC, 2007). Due to a possible cryospheric feedback, the Tibetan Plateau (TP) is known as a "sensitive area" and "startup region" in China and has been characterized as both a "driving force" of and "amplifier" to global and regional climate change (Feng et al., 1998; Kang et al., 2010). Due to its unique physical environment and geographical position, the TP exerts profound thermal and dynamical influences on the atmospheric circulation, and controls regional energy and water cycles having a vital impact on not only China but also the whole of East Asia and even the globe (Duan et al., 2006; GX Wu et al., 2007). Under the impact of both climate change and increased human activities, the fragile environment in the TP has suffered fundamental changes in recent decades. Amongst the consequences there have been: significant rises of temperature and increases in temperature extremes (Liu and Chen, 2000; You et al., 2008a), widespread and accelerated glacier retreat (Yao et al., 2007; Yao et al., 2012), exacerbating degeneration of permafrost ( $T J$ Zhang, 2007), reduced areal coverage of grasslands (Cui and Graf, 2009; Cui et al., 2006), shrinking lake area (GQ Zhang et al., 2011), and dramatic desertification of land (Cui and Graf, 2009; Cui et al., 2006).

Most previous studies have concentrated on trends in temperature and precipitation. Annual mean temperature has increased by $0.16{ }^{\circ} \mathrm{C} / \mathrm{decade}$ during 1961-2002 (Liu and Chen, 2000), and precipitation has exhibited inconsistent trends (Kang et al., 2010). A significant increase in annual 
precipitation and rain days is found in most parts of Tibet during 1971-2005, but decreases have occurred in Qinghai (Ge et al., 2008). During 1971-2000, potential evapotranspiration in the TP has decreased, suggesting more humid conditions in most areas (S H Wu et al., 2007). During 1961-2005, the frequencies of cold days and nights in the TP have reduced at -0.85 and -2.38 days/decade, respectively, while warm days/nights have increased by 1.26 and 2.54 days/decade. This has resulted in a negative trend of $-0.20{ }^{\circ} \mathrm{C} /$ decade for diurnal temperature range (You et al., 2008a).

Although wind data on the TP is scarce, trends in surface wind speed have been studied on global and regional scales (Fu et al., 2011; Guo et al., 2011; Jiang et al., 2010; McVicar et al., 2008; McVicar et al., 2012; Pirazzoli and Tomasin, 2003; Pryor et al., 2009; Tuller, 2004; Xu et al., 2006; Yang et al., 2012; You et al., 2010a). Tuller (2004) found that mean annual wind speeds along the west coasts of Canada had weakened from the 1940s to the 1990s, coinciding with stilling winds in the contiguous United States during 1973-2005 (Pryor et al., 2009). In Australia, about 88\% of stations show negative trends for wind speeds during 1975-2006 (McVicar et al., 2008), consistent with decreasing wind speed at coastal Italian stations from 1951 to the mid-1970s. In lowland China, mean wind speeds during the periods of 1969-2000, 1969-2005, 1969-2009, 1961-2007 and 1956-2004 have been studied and the decline in wind speeds is pronounced, regarded as a cause of decreased surface evaporation and dust storm frequency $(F u$ et al., 2011; Guo et al., 2011; Jiang et al., 2010; Xu et al., 2006; Yang et al., 2012). Comparisons of surface wind speeds with reanalysis wind components including NCEP/NCAR and ERA-40 in the TP (You et al., 2010a), United States (Pryor et al., 2009), and Australia (McVicar et al., 2008), and show that there are discrepancies between reanalyses and observations. Furthermore, IPCC AR5 
models exhibit lower inter-annual variability than reanalyses and observations during 1971-2005, and fail to reproduce the recent decline in wind speed observed in the near-surface observations (Chen et al., 2012).

This study analyzes surface wind speeds on the TP based on surface observations between 1980 and 2005. This is the period which has shown a rapid warming across the region (You et al., 2010a). Spatial and temporal characteristics of the wind field and the forcing factors of surface wind speed are investigated. Understanding these forcing factors will enable future trends in wind speed to be predicted with greater confidence.

\section{Data and methods}

Monthly mean wind speeds at 71 observational stations in the TP were provided by the National Climate Center, China Meteorological Administration (CMA). Stations were selected (Figure 1) according to procedures outlined in previous papers (You et al., 2008a; You et al., 2010a). Chosen stations are all above $2000 \mathrm{~m}$ above sea level, and a histogram showing the distribution of station elevations can be found in Figure 2 in You et al., (2010a). As the method of wind speed observation was changed at the beginning of the 1970s (Xu et al., 2006), data for the period of 1980-2005 are selected in this study, excluding the earlier part of the dataset. In order to examine causes of changes in wind speed, the mean monthly temperature, maximum and minimum temperature, and sunshine duration were also selected for each station. A TP geopotential height index was calculated as the accumulated value of $500 \mathrm{hPa}$ geopotential height above $5000 \mathrm{~m}$ (based on adding up each grid point over the region of $30^{\circ} \mathrm{N}-40^{\circ} \mathrm{N}, 75^{\circ} \mathrm{E}-105^{\circ} \mathrm{E}$ ). For example, a height of $5730 \mathrm{~m}$ would give a value of 730 . Higher geopotential heights (higher TP index) means higher atmospheric pressure over the region. The 500 geopotential heights are taken from the 
Reanalysis (NCEP/NCAR hereafter), which is provided by the National Oceanic and Atmospheric fields from the NCEP/NCAR reanalysis.

The Mann-Kendall test for a trend with Sen's slope estimates was used to detect and estimate

$$
\left.S=\sum_{k=1}^{n-1} \sum_{j=k+1}^{n} \operatorname{sgn}\left(x_{j}-x_{k}\right) \quad \operatorname{sgn} x_{j}-x_{k}\right)=\left\{\begin{array}{clc}
+1 & \text { if } & x_{j}-x_{k}>0 \\
0 & \text { if } & x_{j}-x_{k}=0 \\
1 & \text { if } & x_{j}-x_{k}<0
\end{array}\right\}
$$

$$
\operatorname{Var}(\mathrm{S})=\frac{n(n-1)(2 n+5)-\sum_{p=1}^{q} t_{p}\left(t_{p}-1\right)\left(2 t_{p}+5\right)}{18}
$$

The test statistic $\mathrm{Z}$ is estimated as:

$$
Z=\left\{\begin{array}{ccc}
\frac{S-1}{\sqrt{\operatorname{VAR}(S)}} & \text { if } & S>0 \\
0 & \text { if } & S=0 \\
\frac{S+1}{\sqrt{\operatorname{VAR}(S)}} & \text { if } & S<0
\end{array}\right.
$$


given as follows:

$$
Q=\operatorname{Median}\left(\frac{x_{j}-x_{k}}{j-k}\right) ; i=1, \ldots \ldots . . .
$$

A trend is considered to be statistically significant if $\mathrm{P}<0.05$.

\section{Results and Discussion}

\subsection{The temporal and spatial distribution of wind speed}

Figure 1 shows the distribution of mean wind speed over the TP during 1980-2005. The mean annual wind speed (top panel) gradually increases from the south-east to the north-west. The maximum mean wind speed occurs in the Hoh Xil area and the Qaidam Basin, with smaller values in the south and east of the TP. The minimum mean wind speed is recorded in eastern Tibet and northern Sichuan. The mean annual mean wind speed is $2.25 \mathrm{~m} / \mathrm{s}$, but individual stations range from $4.98 \mathrm{~m} / \mathrm{s}$ in Wushaoling, Gansu, to $0.96 \mathrm{~m} / \mathrm{s}$ in Qamdo, Tibet.

Seasonal mean wind speed patterns are broadly similar to the annual pattern, with increases from the south-east to the north-west. In all seasons there is a relative minimum of wind speed where the three provinces of Tibet, Sichuan, and Qinghai meet. Maximum mean wind speed occurs in spring $(2.78 \mathrm{~m} / \mathrm{s}$ ), and values range from $5.69 \mathrm{~m} / \mathrm{s}$ to $1.27 \mathrm{~m} / \mathrm{s}$ (Maerkang in Sichuan). Winter is almost as windy (mean $2.18 \mathrm{~m} / \mathrm{s}$ ), with a maximum of $5.21 \mathrm{~m} / \mathrm{s}$ (Wudaoliang, Qinghai) and a minimum of $0.78 \mathrm{~m} / \mathrm{s}$ (Qamdo, Tibet). In both winter and spring, surface and upper atmospheric circulation is controlled by the prevailing westerly wind belt (Kang et al., 2010), resulting in stronger wind speeds overall. In summer, and to a lesser extent in autumn, the establishment and northward propagation of the south-west Indian monsoon and the movement of the upper westerly circulation system to the north, reduces mean wind speeds. The summer mean is $2.12 \mathrm{~m} / \mathrm{s}$, with a maximum of $4.75 \mathrm{~m} / \mathrm{s}$ and minimum of $0.83 \mathrm{~m} / \mathrm{s}$ (Yushu, Qinghai). Autumn is even less windy 
153

154

155

156

157

158

159

160

161

162

163

164

(mean $1.91 \mathrm{~m} / \mathrm{s}$ ) with a maximum of $4.72 \mathrm{~m} / \mathrm{s}$ and minimum of $0.77 \mathrm{~m} / \mathrm{s}$ in Qamdo, Tibet.

\subsection{Trend analysis of wind speed since 1980}

Figure 2 shows time series of wind speed over the whole TP during 1980-2005 on both an annual (top panel) and seasonal basis (other panels). Annual wind speed shows a statistically significant decrease of $-0.24 \mathrm{~m} / \mathrm{s} /$ decade $(\mathrm{P}<0.0001$ ) (You et al., 2010a). The decrease is rapid since 1990 and the lowest value was recorded in 2002. Since then there has been a slight short-term recovery.

The decrease is widespread with $87 \%$ of stations showing decreasing trends (significant at $66 \%$ of all stations). Trend magnitudes vary from $-1.16 \mathrm{~m} / \mathrm{s} / \mathrm{decade}$ to $-0.25 \mathrm{~m} / \mathrm{s} / \mathrm{decade}$. The strongest decreases appear to be concentrated around the northwestern Qaidam Basin, and parts of the south west and south east of the TP, consistent with rapid increases of the annual mean temperature in the same regions (Kang et al., 2010; You et al., 2008a). Further analysis of this relationship is discussed in section 3.3.1.

Seasonal wind speeds on the TP also show significant negative trends during 1980-2005. Wind speeds in all seasons are positively correlated with the annual mean, particularly in spring $(\mathrm{r}=0.94)$ and summer $(\mathrm{r}=0.96)$, so are expected to have broadly similar trends. Again trends are steepest in north-western and south-western parts of the TP. The spring decrease averages $-0.29 \mathrm{~m} / \mathrm{s}(\mathrm{P}<0.05)$ and about $89 \%$ of stations show a decrease (62\% significantly so). Summer also has a significant reduction of $0.24 \mathrm{~m} / \mathrm{s} / \mathrm{decade}$, with $93 \%(62 \%)$ of the stations showing negative (significant negative) trends. Rates for autumn and winter are slightly weaker at -0.19 and $-0.23 \mathrm{~m} / \mathrm{s} / \mathrm{decade}$, respectively, with $89 \%(51 \%)$ and $89 \%(44 \%)$ of stations showing decreases (statistically significant decreases) (You et al., 2010a). 


\subsection{Wind speed forcing factors}

The following sections examine the relationships between wind speed changes and various air temperatures, solar radiation, atmospheric dynamics (as measured by the TP index) and elevation.

\subsubsection{Relationship between wind speed and air temperature}

Table 1 lists annual and seasonal trends of mean, minimum and maximum temperature in the TP during 1980-2004. Stations are selected from the China homogenized historical temperature dataset (1951-2004, version 1.0) (Li et al., 2004), from the China Meteorological Administration. All mean temperatures, maximum and minimum temperatures show a significant increase. In most seasons warming rates for minimum temperature are more rapid than for maximum temperatures, thus leading to a reduced diurnal temperature range in the TP, consistent with previous studies (Kang et al., 2010; You et al., 2008a). Table 2 summarizes correlation coefficients between wind speed and mean, maximum and minimum temperature. Wind speed is negatively correlated with all three temperatures. Highly significant relationships occur both on an annual basis $(r=-0.60$, $\mathrm{p}<0.001$ for minimum temperatures) and in summer and autumn ( $\mathrm{P}<0.001)$. Strong negative relationships with minimum temperatures are particularly surprising since one might expect cold air drainage to encourage lower minima when conditions are calm (this would lead to a positive relationship). However this effect is overridden, and suggests that larger scale mechanical forces are just as influential. Weakening wind speeds are associated with rising temperatures in the TP, especially at night.

The horizontal pressure gradient is a direct cause of horizontal air flow. This in turn is driven by the horizontal temperature gradient (You et al., 2010a). To examine whether weakening wind speed may be a result of larger scale weakened temperature (and thus pressure) gradients, the 
relationships between mean annual wind speed, surface temperature and pressure gradients were examined between low latitude $\left(20^{\circ} \mathrm{N}-25^{\circ} \mathrm{N} ; 85^{\circ} \mathrm{E}-105^{\circ} \mathrm{E}\right)$, middle latitude $\left(35^{\circ} \mathrm{N}-40^{\circ} \mathrm{N}\right.$; $\left.85^{\circ} \mathrm{E}-105^{\circ} \mathrm{E}\right)$ and high latitude $\left(50^{\circ} \mathrm{N}-55^{\circ} \mathrm{N} ; 85^{\circ} \mathrm{E}-105^{\circ} \mathrm{E}\right)$ bands (Figure 4), again using NCEP/NCAR reanalysis data. Wind speed has significant positive correlations not only with the surface temperature gradient between different latitudinal bands (Figure $4 a, b$ ) but also the surface pressure gradient in the same bands (Figure $4 \mathrm{c}, \mathrm{d}$ ). Clearly surface temperature and pressure gradients are positively correlated (Figure 4e, f). In previous work (You et al., 2010a), it has been demonstrated that asymmetric warming trends in low, middle and high latitudinal bands have caused significant weakening in the latitudinal pressure gradients (both low to mid, and mid to high latitudes). This will lead to a regional decrease of horizontal temperature and pressure gradients and thus weaker winds. In winter this effect is dominated by warmer and more rapid warming in the north of the country, whereas in summer, slight cooling in the south east of China and warming over adjacent seas has weakened the land-sea temperature difference and therefore thermally generated wind speeds (Guo et al., 2011; Xu et al., 2006).

\subsubsection{Relationship between wind speed and sunshine duration}

Table 1 also shows that annual and seasonal sunshine duration in the TP during 1980-2005 have significantly decreased with an annual reduction of -65.12 hours/decade $(\mathrm{P}<0.01)$, and an even steeper reduction in percentage terms in summer. The dimming may be associated with the observed increase in total cloud amount, especially low cloud cover, and an increase in atmospheric water vapor pressure and precipitation, as well as increased atmospheric aerosol content (Wild, 2009; You et al., 2010b). Figure 3d illustrates that annual wind speed shows a positive correlation with sunshine duration $(\mathrm{r}=0.59: \mathrm{P}<0.001)$. The relationship also holds in most 
seasons, apart from winter (Table 2). Despite the TP having the highest mean income of solar radiation in China, even here incoming solar radiation appears to be declining, consistent with dimming reported across the globe since the beginning of 1960s (Wild, 2009; You et al., 2010b). This is not inconsistent with warming temperatures. Greenhouse warming is manifest more clearly at night, but even during the day, increased greenhouse long wave absorption would more than offset any cooling effect which would result due to dimming of solar radiation. Decreasing sunshine duration is also likely to weaken turbulence and atmospheric instability in the surface boundary layer, contributing to the overall reduction in wind speed.

\subsubsection{Relationship between wind speed and Tibetan Plateau index}

Table 1 also lists trends in the annual and seasonal TP index during 1980-2005. The index is essentially one of anticyclonicity with higher accumulated heights meaning higher atmospheric pressure over the plateau (and warmer air). The index shows positive trends over the period for all seasons, in accordance with general warming in the region (Fu et al., 2011; Liu and Chen, 2000; You et al., 2008a). The most pronounced upward trend occurs in winter with a rate of 10.30 $\mathrm{m} /$ decade $(\mathrm{P}<0.05)$, and only the trend in summer is insignificant. On an annual scale, wind speed is negatively correlated with the TP index $(\mathrm{r}=-0.68: \mathrm{P}<0.0001)$. Negative correlations also occur in all four seasons, especially in autumn $(\mathrm{r}=-0.73, \mathrm{P}<0.05)$ (Table 2$)$. The TP is known to influence global and regional atmospheric circulation systems, such as mid-latitude westerlies and the Asian monsoon, through its powerful thermal and dynamic role (Duan et al., 2006; Kang et al., 2010; G X Wu et al., 2007; Yao et al., 2007; Yao et al., 2012). An increasing TP index is therefore consistent with weaker surface wind speeds over the TP, but how this relates to long term changes in the mechanical and thermal forcing of the large scale circulation requires more research. A 
weakening of surface airflow over the TP, which at the height concerned $(500 \mathrm{mb})$ is at the level of the westerly jet stream, suggests that the westerly circulation may have weakened. This would be consistent with the enhanced warming reported in the northern parts of the plateau (in comparison with the south) which would weaken the meridional temperature gradient (and hence pressure gradient) - see section 3.3.1. In summer however, monsoon winds are known to have weakened (Xu et al. 2006) which would also be consistent with a weakening of the thermal low pressure center (and thus an increase in TP index) with relatively rising pressure heights over the TP. However this is the only season in which the trend in TP index is insignificant in our study, so patterns are a lot less clear in this season.

\subsubsection{Relationship between wind speed and elevation}

Since topography and elevation can influence spatial patterns of wind speed in the TP (You et al., 2010a) we examined the relationship between wind speed trends and elevation. Figure 5 shows the relationship between elevation and trend magnitude in wind speed during the studied period, and there is no strong pattern. Wind speed declines more or less consistently in all elevation bands, inconsistent with results from the south west of China (Yang et al., 2012). Yang et al. (2012) demonstrated that the decrease of the mean wind speed was more pronounced at higher elevations in the Yungui Plateau of China, and that the correlation between elevation and trends of wind speed was statistically significant. However in that study all stations were below $1500 \mathrm{~m}$. The failure to capture the elevation dependency above $2000 \mathrm{~m}$ in our study is in accordance with results examining trends in temperature and temperature extremes (You et al., 2008b). Future studies are required to understand the inconsistent results on this issue (Rangwala and Miller, 2012). 


\section{Possible causes of weakening wind speed in the TP}

264 Our analysis has demonstrated strong decreasing trends in wind speeds over the TP. These are

265 associated with increased air temperatures, decreased meridional temperature and pressure

266 gradients, decreased solar radiation and an increased TP index. Whilst many of these changes are

267 consistent, it is important to understand the broader scale physical processes at work. In theory weakening wind speed could originate from a number of factors, which can be divided into two categories: natural and anthropogenic. Possible natural causes include increasing land surface roughness due to an increase in vegetation cover (McVicar et al., 2012; Vautard et al., 2010), a weakened meridional pressure gradient caused by asymmetric global warming (Guo et al., 2011; You et al., 2010a), regional and global changes in atmospheric circulation (Vautard et al., 2010), changes in synoptic scale storm patterns (Klink, 1999), and topographic effects (You et al., 2010a). Anthropogenic causes include land use change (Klink, 1999; 2002), urbanization (Ren et al., 2008), anthropogenic emissions and air pollution (Klink, 1999; 2002), and changes of wind speed measurement, site maintenance and wind speed sensors (McVicar et al., 2012). Both natural and anthropogenic causes interact to some extent. For example, both human air pollution such as coal construction, can modify surface roughness and alter atmospheric stability in a similar way to natural vegetation cover, increasing friction and reducing kinetic energy of horizontal airflow, thus reducing wind speed (McVicar et al., 2012; Pryor et al., 2009; Xu et al., 2006). However, compared with eastern China, the TP is influenced relatively less by human activities and its wind observations affected less by urbanization. Therefore natural causes are more likely to be the dominant influence on the trends seen in this analysis. 


\section{Conclusion}

Spatial and temporal patterns of mean wind speed at 71 stations in the TP are examined, long term trends are described, and the relationships between wind speed and a number of related factors (sunshine duration, air temperature, temperature gradients and the TP index) are analyzed during 1980-2005. The following conclusions are drawn.

(1) Annual and seasonal mean wind speeds in the TP during 1980-2005 gradually increase from the south-east to the north-west of the region. Highest mean wind speeds occur in the Hoh Xil, Qaidam Basin, and a relative minimum occurs at the junction of Qinghai, Sichuan and Tibet. In most regions, spring is the windiest season, followed by winter, summer and then autumn.

(2) During 1980-2005, the regional annual wind speed has shown a significant decrease with a rate of $0.24 \mathrm{~m} / \mathrm{s} / \mathrm{decade}$. A (statistically significant) decrease is shown at (66\%) $87 \%$ of stations. Most stations with the steepest declines are in north-western and south-western areas but are not solely in these regions. The rate of decline accelerates after 1990, and lowest values were reached in 2002. Winds also show significant reductions in individual seasons, particularly in spring $(0.29 \mathrm{~m} / \mathrm{s} /$ decade $(\mathrm{P}<0.05))$ and summer $(0.24 \mathrm{~m} / \mathrm{s} /$ decade $)$.

(3) During the same period, annual and seasonal mean temperature, maximum and minimum temperature, and the TP index (mean geopotential height) show significant increases, while sunshine duration has declined. In most cases, wind speed is significantly positively correlated correlated with sunshine duration, suggesting that those factors contribute to the change of observed wind speed. Climate warming may weaken the meridional temperature gradient and hence pressure gradient, which would account for weakening of wind speed in this region. 
311 suggestions.

312

313

314

315

316

317

318

319

320

321

322

323

324

325

326

327

328 


\section{References}

Chen, L., S. C. Pryor, and D. L. Li (2012), Assessing the performance of Intergovernmental Panel on Climate Change AR5 climate models in simulating and projecting wind speeds over China, $J$.

Geophys. Res.-Atmos., 117, D24102.

Cui, X. F., and H. F. Graf (2009), Recent land cover changes on the Tibetan Plateau: a review, Clim. Change, 94(1-2), 149-163.

Cui, X. F., H. F. Graf, B. Langmann, W. Chen, and R. H. Huang (2006), Climate impacts of anthropogenic land use changes on the Tibetan Plateau, Glob. Planet. Change, 54(1-2), 33-56.

Duan, A. M., G. X. Wu, Q. Zhang, and Y. M. Liu (2006), New proofs of the recent climate warming over the Tibetan Plateau as a result of the increasing greenhouse gases emissions, Chinese Science Bulletin, 51(11), 1396-1400.

Feng, S., M. Tang, and W. Dongmei (1998), New evidence supports that the Tibetan Plateau is the trigger region of China Chin. Sci. Bull., 43, 633-636

Fu, G. B., J. J. Yu, Y. C. Zhang, S. S. Hu, R. L. Ouyang, and W. B. Liu (2011), Temporal variation of wind speed in China for 1961-2007, Theoretical and Applied Climatology, 104(3-4), 313-324.

Ge, S., X. P. Tang, and H. Y. Lu (2008), Climatic characteristics of rainfall and rainy days during the last 35 years over the Qinghai-Xizang Plateau, Acta Geographica Sinica, 63, 924-930.

Guo, H., M. Xu, and Q. Hu (2011), Changes in near-surface wind speed in China: 1969-2005, Int. J. Climatol., 31(3), 349-358.

IPCC (2007), Summary for Policymakers of Climate change 2007: The Physical Science Basis. Contribution of Working Group I to the Fourth Assessment Report of the Intergovernmental Panel on Climate Change Cambridge, UK: Cambridge University Press. 
Jiang, Y., Y. Luo, Z. C. Zhao, and S. W. Tao (2010), Changes in wind speed over China during 1956-2004, Theoretical and Applied Climatology, 99(3-4), 421-430.

Kalnay, E., et al. (1996), The NCEP/NCAR 40-year reanalysis project, Bulletin of the American Meteorological Society, 77(3), 437-471.

Kang, S. C., Y. W. Xu, Q. L. You, W. A. Flugel, N. Pepin, and T. D. Yao (2010), Review of climate and cryospheric change in the Tibetan Plateau, Environ. Res. Lett., 5(1), 015101.

Klink, K. (1999), Trends in mean monthly maximum and minimum surface wind speeds in the coterminous United States, 1961 to 1990, Clim. Res., 13(3), 193-205.

Klink, K. (2002), Trends and interannual variability of wind speed distributions in Minnesota, $J$. Clim., 15(22), 3311-3317.

Li, Q. X., X. N. Liu, H. Z. Zhang, T. C. Peterson, and D. R. Easterling (2004), Detecting and adjusting temporal inhomogeneity in Chinese mean surface air temperature data, Advances in Atmospheric Sciences, 21(2), 260-268.

Liu, X. D., and B. D. Chen (2000), Climatic warming in the Tibetan Plateau during recent decades, International Journal of Climatology, 20(14), 1729-1742.

McVicar, T. R., T. G. Van Niel, L. T. Li, M. L. Roderick, D. P. Rayner, L. Ricciardulli, and R. J. Donohue (2008), Wind speed climatology and trends for Australia, 1975-2006: Capturing the stilling phenomenon and comparison with near-surface reanalysis output, Geophys. Res. Lett., $35(20)$.

McVicar, T. R., et al. (2012), Global review and synthesis of trends in observed terrestrial near-surface wind speeds: Implications for evaporation, J. Hydrol., 416, 182-205.

Pirazzoli, P. A., and A. Tomasin (2003), Recent near-surface wind changes in the central 
Mediterranean and Adriatic areas, International Journal of Climatology, 23(8), 963-973.

Pryor, S. C., R. J. Barthelmie, D. T. Young, E. S. Takle, R. W. Arritt, D. Flory, W. J. Gutowski, A. Nunes, and J. Roads (2009), Wind speed trends over the contiguous United States, J. Geophys. Res.-Atmos., 114.

Rangwala, I., and J. R. Miller (2012), Climate change in mountains: a review of elevation-dependent warming and its possible causes, Climatic Change, 114(3-4), 527-547.

Ren, G. Y., Y. Q. Zhou, Z. Y. Chu, J. X. Zhou, A. Y. Zhang, J. Guo, and X. F. Liu (2008), Urbanization effects on observed surface air temperature trends in north China, J. Clim., 21(6), $1333-1348$.

Sen, P. K. (1968), Estimates of regression coefficient based on Kendall's tau, Journal of the American Statistical Association, 63, 1379-1389.

Tuller, S. E. (2004), Measured wind speed trends on the west coast of Canada, International Journal of Climatology, 24(11), 1359-1374.

Vautard, R., J. Cattiaux, P. Yiou, J. N. The paut, and P. Ciais (2010), Northern Hemisphere atmospheric stilling partly attributed to an increase in surface roughness, Nature Geoscience, $756-761$.

Wild, M. (2009), Global dimming and brightening: A review, Journal of Geophysical Research-Atmospheres, 114, D00D16.

Wu, G. X., Y. M. Liu, T. M. Wang, R. J. Wan, X. Liu, W. P. Li, Z. Z. Wang, Q. Zhang, A. M. Duan, and X. Y. Liang (2007), The influence of mechanical and thermal forcing by the Tibetan Plateau on Asian climate, Journal of Hydrometeorology, 8(4), 770-789.

Wu, S. H., Y. H. Yin, D. Zheng, and Q. Y. Yang (2007), Climatic trends over the Tibetan Plateau 
during 1971-2000, J. Geogr. Sci., 17(2), 141-151.

Xu, M., C. P. Chang, C. B. Fu, Y. Qi, A. Robock, D. Robinson, and H. M. Zhang (2006), Steady decline of east Asian monsoon winds, 1969-2000: Evidence from direct ground measurements of wind speed, J. Geophys. Res.-Atmos., 111(D24).

Yang, X. M., Z. X. Li, Q. Feng, Y. Q. He, W. L. An, W. Zhang, W. H. Cao, T. F. Yu, Y. M. Wang, and W. H. Theakstone (2012), The decreasing wind speed in southwestern China during 1969-2009, and possible causes, Quaternary International, 263, 71-84.

Yao, T. D., J. Pu, A. Lu, Y. Wang, and W. Yu (2007), Recent glacial retreat and its impact on hydrological processes on the tibetan plateau, China, and sorrounding regions, Arctic Antarctic and Alpine Research, 39(4), 642-650.

Yao, T. D., et al. (2012), Different glacier status with atmospheric circulations in Tibetan Plateau and surroundings, Nature climate change, 2(9), 663-667.

You, Q. L., S. C. Kang, E. Aguilar, and Y. P. Yan (2008a), Changes in daily climate extremes in the eastern and central Tibetan Plateau during 1961-2005, J. Geophys. Res.-Atmos., 113(D07101).

You, Q. L., S. C. Kang, N. Pepin, and Y. P. Yan (2008b), Relationship between trends in temperature extremes and elevation in the eastern and central Tibetan Plateau, 1961-2005, Geophysical Research Letters, 35, L04704.

You, Q. L., S. C. Kang, W. A. Flugel, N. Pepin, Y. P. Yan, and J. Huang (2010a), Decreasing wind speed and weakening latitudinal surface pressure gradients in the Tibetan Plateau, Clim. Res., 42(1), 57-64.

You, Q. L., S. C. Kang, W. A. Flugel, A. Sanchez-Lorenzo, Y. P. Yan, J. Huang, and J. Martin-Vide (2010b), From brightening to dimming in sunshine duration over the eastern and central Tibetan 

the Tibetan Plateau using ICESat altimetry data (2003-2009), Remote Sensing of Environment, $115(7), 1733-1742$.

421 Zhang, T. J. (2007), Perspectives on environmental study of response to climatic and land 


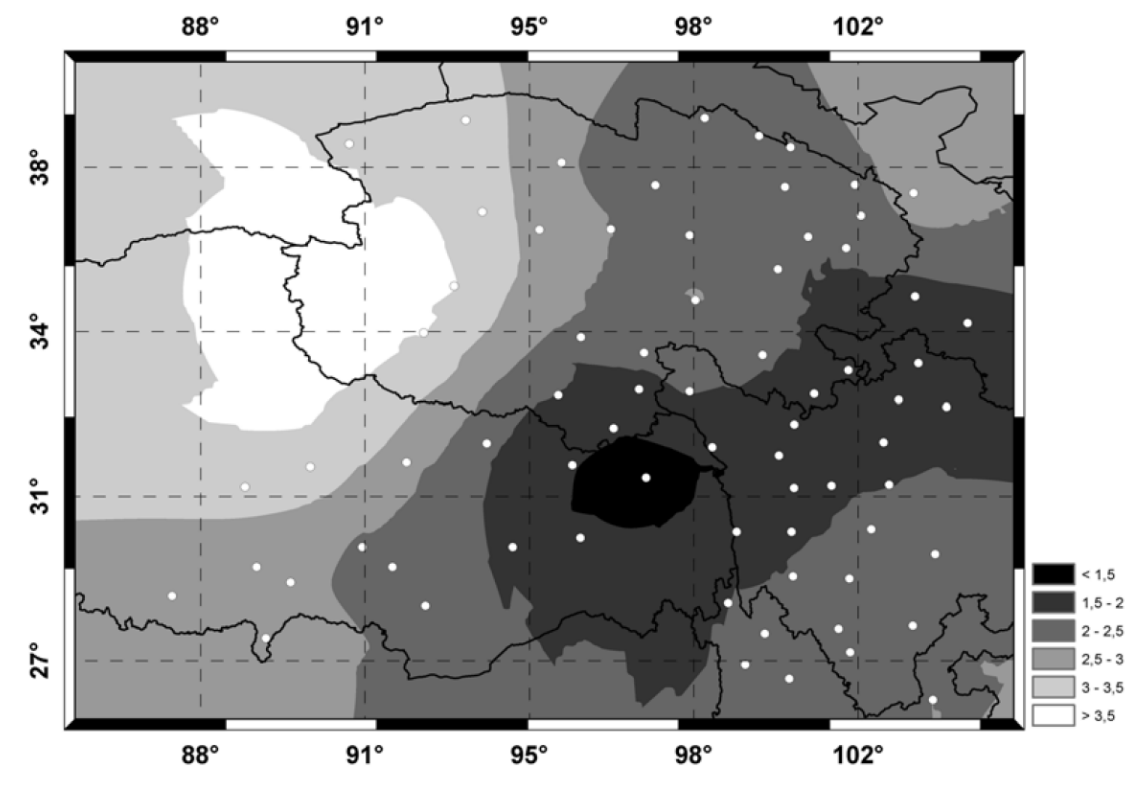

Annual
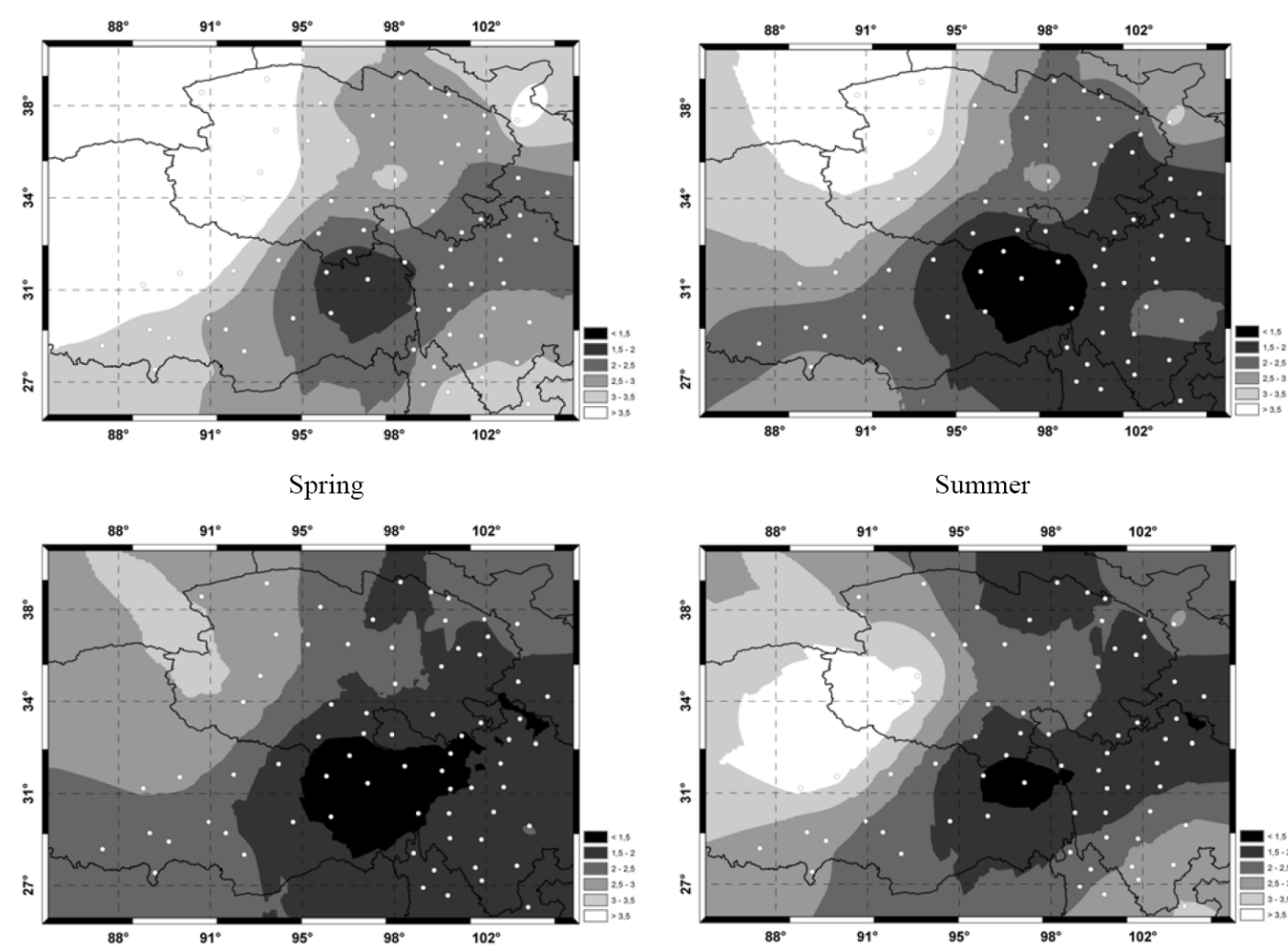

Autumn

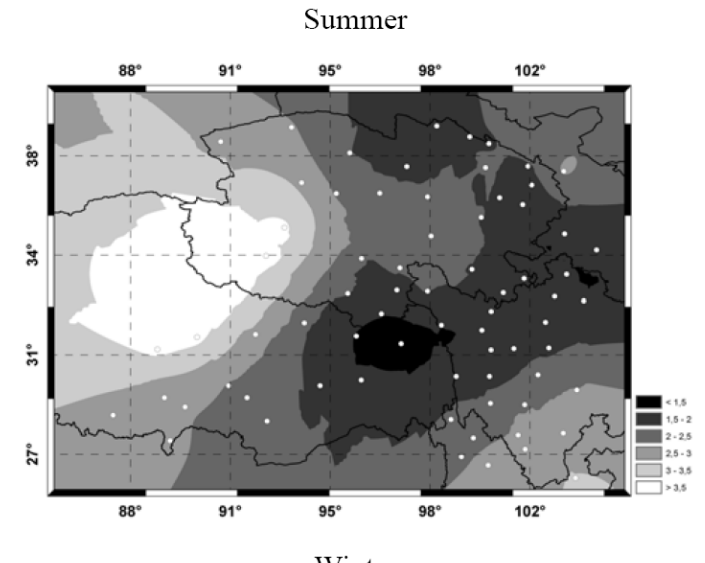

Figure 1 The spatial patterns of annual and seasonal mean wind speed in the Tibetan Plateau 

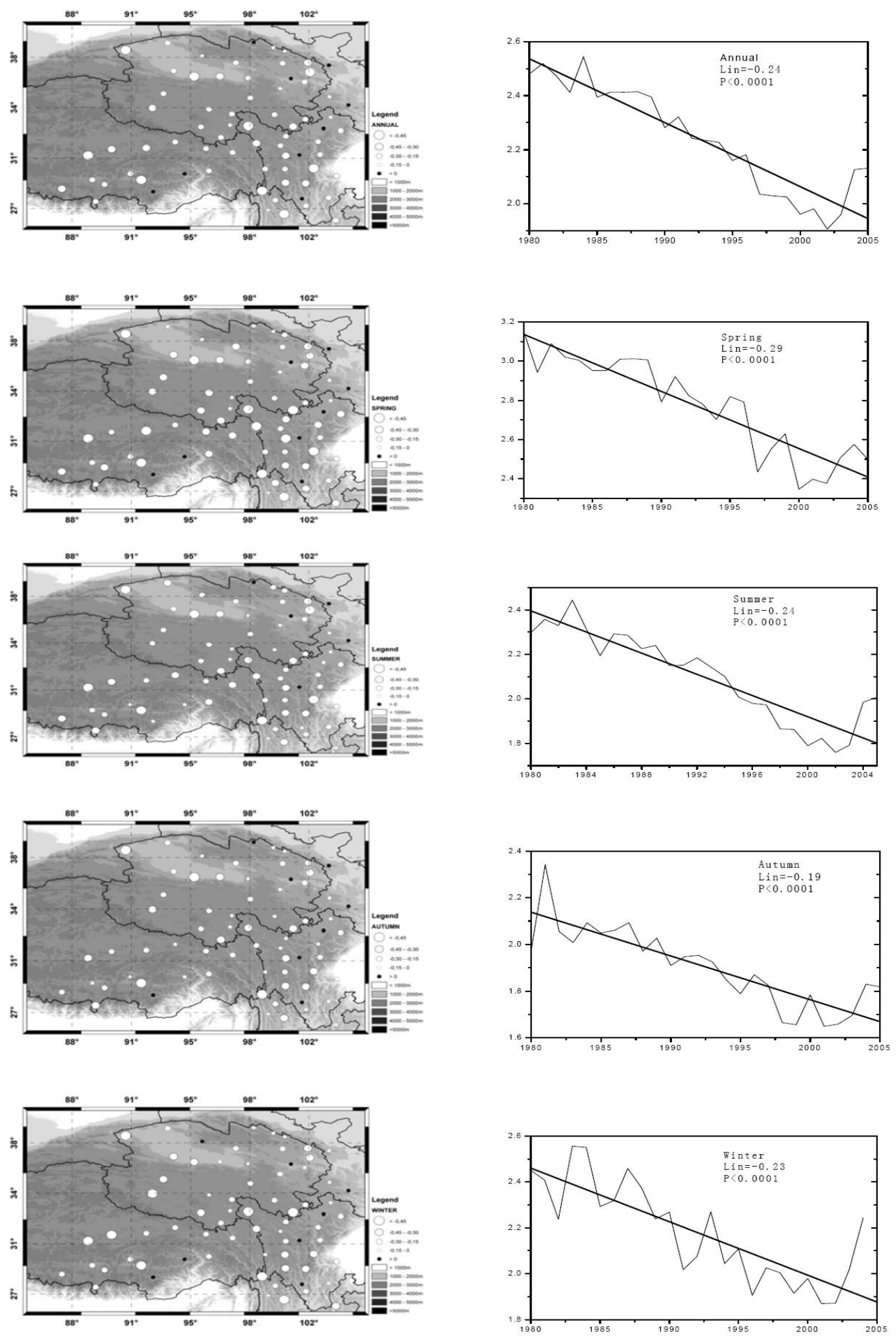

Figure 2 Maps of trend magnitude (from top left: annual, spring (MAM), summer (JJA), autumn $(\mathrm{SON})$ and winter $(\mathrm{DJF}))$ for mean annual/seasonal wind speed $(\mathrm{m} / \mathrm{s})$. Trend magnitudes are in $\mathrm{m} / \mathrm{s} /$ decade. Graphs (from top right: annual, spring, summer, autumn, winter) of regionwide mean wind speed between 1980 and 2005. Lin represents the gradient of the trendline (converted to 

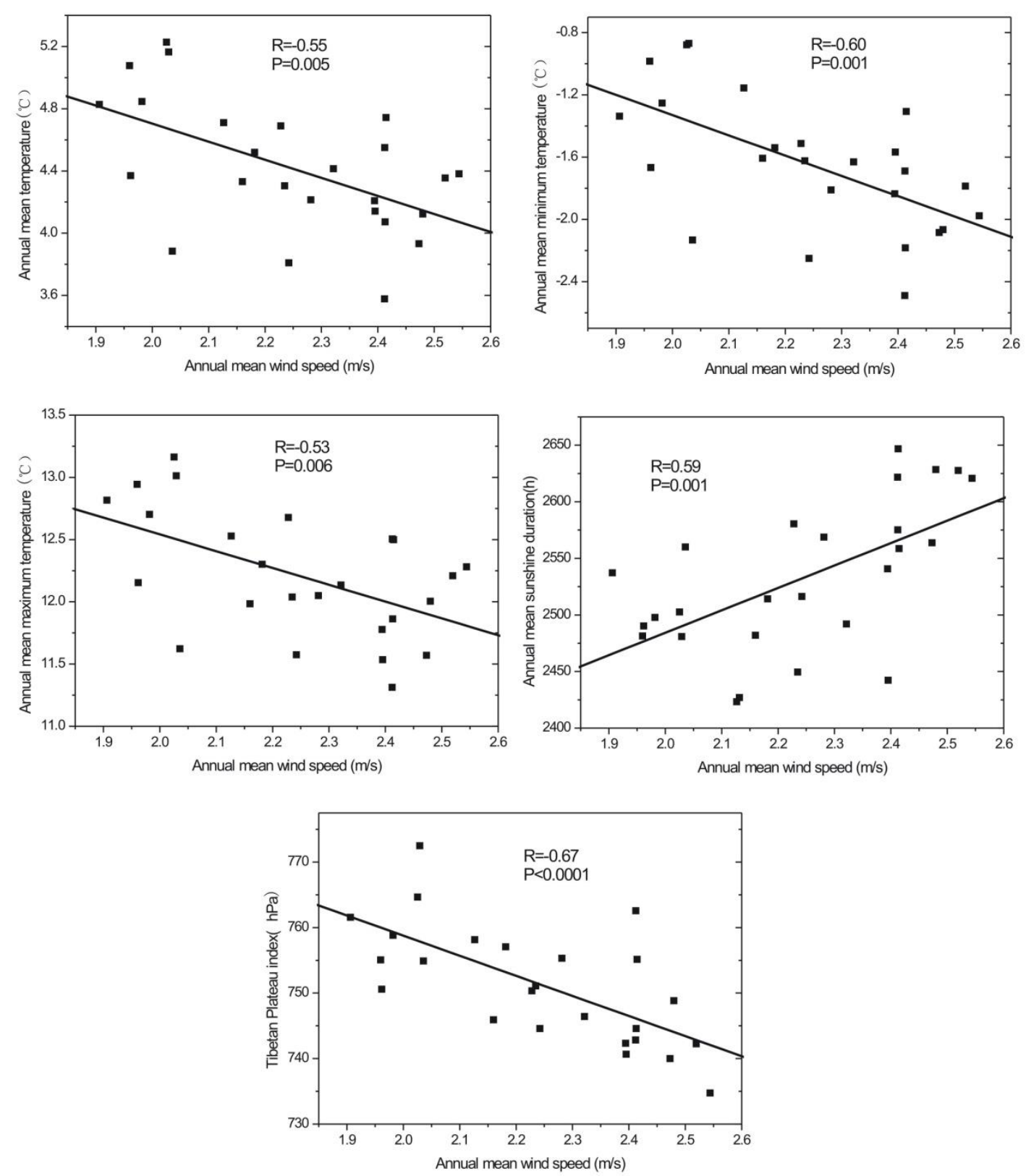

465 Figure 3 Relationships between annual mean wind speed and a) annual mean air temperature (top

466 left), b) annual mean minimum air temperature (top right), c) annual mean maximum air 467 temperature (middle left), d) annual mean sunshine duration (middle right) and e) Tibetan Plateau 468 index (bottom) in the Tibetan Plateau during 1980-2004. R is the correlation coefficient and P the significance level 


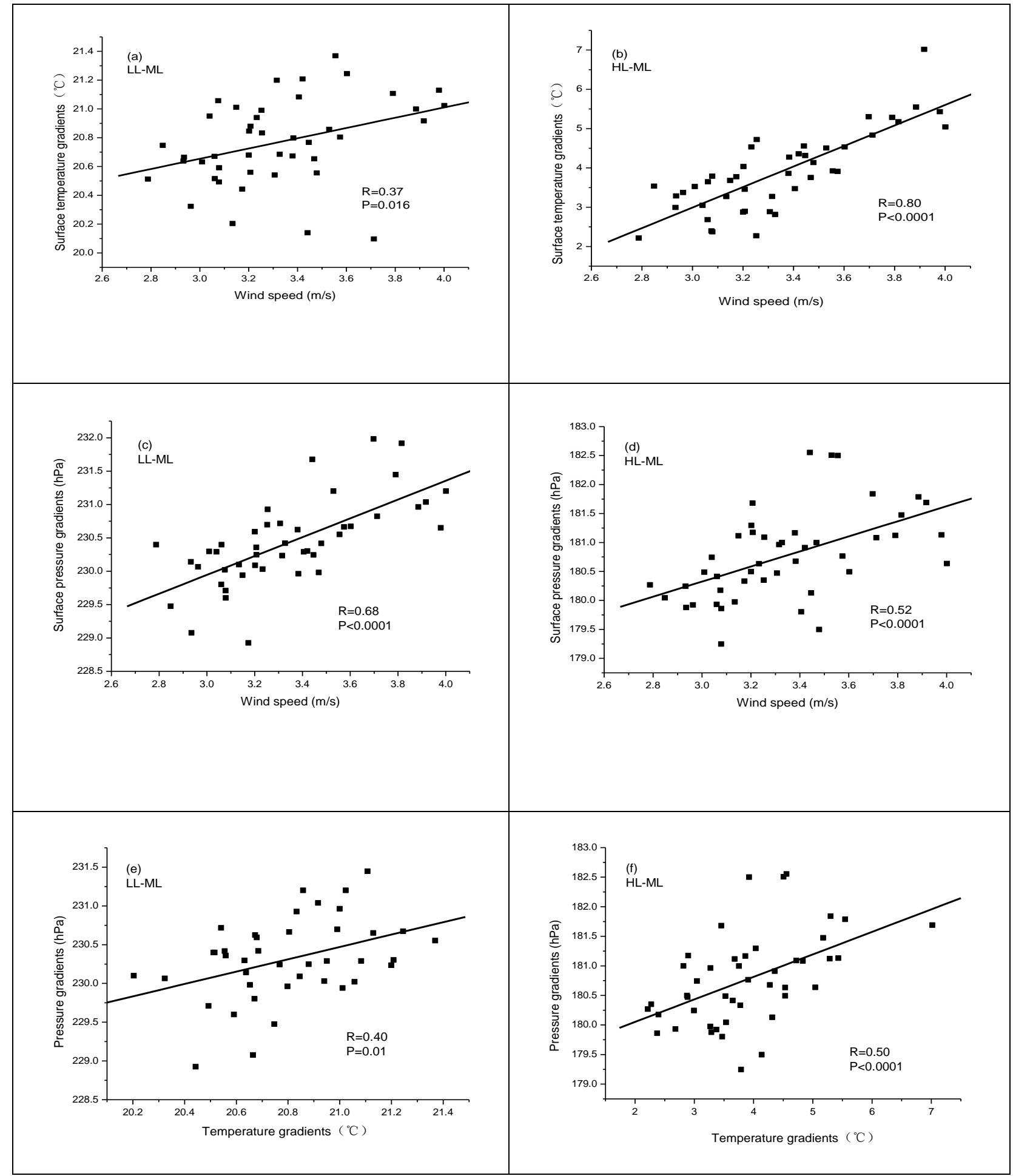

471 Figure 4 Relationships between annual regionwide mean wind speed, annual surface temperature

472 gradients, and annual surface pressure gradients during 1961-2005. The straight lines are linear fits,

473 and $\mathrm{R}$ stands for the correlation coefficient and $\mathrm{P}$ for statistical significance. Three regions of the

474 Tibetan Plateau $\left(85^{\circ} \mathrm{E}-105^{\circ} \mathrm{E}\right)$ are defined based on NCEP/NCAR reanalysis to define the 
480

481

482

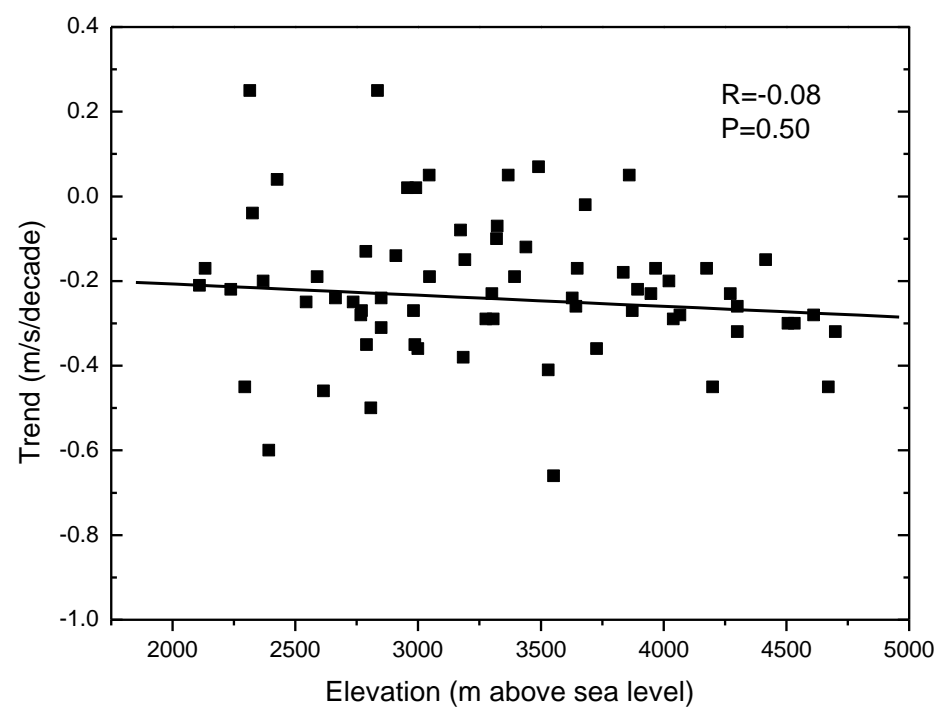
latitudes (LL-ML), and right hand panels to middle vs high laitutdes (ML-HL)
483

meridional temperature/pressure gradients: low latitude (LL) $\left(20^{\circ} \mathrm{N}-25^{\circ} \mathrm{N}\right)$, middle latitude (ML) $\left(35^{\circ} \mathrm{N}-40^{\circ} \mathrm{N}\right)$, and high latitude (HL) $\left(50^{\circ} \mathrm{N}-55^{\circ} \mathrm{N}\right)$. Left hand panels relate to low vs middle 
Table 1 Trends of mean air temperature, mean minimum air temperature, mean maximum air temperature, sunshine duration and the Tibetan Plateau index in the central and eastern Tibetan

Plateau during 1980-2004 on an annual and seasonal basis

\begin{tabular}{lccccc}
\hline & Annual & Spring & Summer & Autumn & Winter \\
\hline Mean temperature $\left({ }^{\circ} \mathrm{C} /\right.$ decade $)$ & $0.34^{* *}$ & $0.38^{* *}$ & $0.31^{* *}$ & $0.38^{*}$ & 0.34 \\
Minimum temperature $\left({ }^{\circ} \mathrm{C} /\right.$ decade $)$ & $0.39^{* * *}$ & $0.43^{* *}$ & $0.38^{* *}$ & $0.44^{*}$ & $0.42^{*}$ \\
Maximum temperature $\left({ }^{\circ} \mathrm{C} /\right.$ decade $)$ & $0.42^{* *}$ & $0.46^{* *}$ & $0.32^{*}$ & 0.40 & 0.32 \\
Sunshine duration $(\mathrm{hr} /$ decade $)$ & $-65.12^{* * *}$ & $-16.33^{* * *}$ & $-25.14^{*}$ & $-12.57^{*}$ & $-13.60^{*}$ \\
Tibetan Plateau index $(\mathrm{m} /$ decade $)$ & $8.08^{* * *}$ & $9.32^{* *}$ & $4.02^{*}$ & $7.04^{* *}$ & $10.30^{* *}$ \\
\hline
\end{tabular}

496 Note: *** means $\mathrm{P}<0.01, * *$ means $\mathrm{P}<0.05$ and $*$ means $\mathrm{P}<0.1$

497

498

499

500

501

502

503

504

505

506

507

508

509

510

511

512 Table 2 Correlation coefficients between mean wind speed $(\mathrm{m} / \mathrm{s})$ and mean air temperature $\left({ }^{\circ} \mathrm{C}\right)$,

513 mean minimum air temperature $\left({ }^{\circ} \mathrm{C}\right)$, mean maximum air temperature $\left({ }^{\circ} \mathrm{C}\right)$, sunshine duration $(\mathrm{hrs})$

514 and the Tibetan Plateau index (m) during 1980-2004 on an annual and seasonal basis

\begin{tabular}{lccccc}
\hline & Annual & Spring & Summer & Autumn & Winter \\
\hline Mean temperature & $-0.55^{* * *}$ & -0.31 & $-0.59^{* * *}$ & $-0.60^{* * *}$ & -0.05 \\
Minimum temperature & $-0.60^{* * *}$ & -0.40 & $-0.56^{* * *}$ & $-0.63^{* * *}$ & -0.11 \\
Maximum temperature & $-0.53^{* * *}$ & -0.32 & $-0.46^{* *}$ & $-0.56^{* * *}$ & -0.07 \\
Sunshine duration & $0.59^{* * *}$ & $0.48^{* *}$ & $0.42^{* *}$ & $0.50^{* * *}$ & 0.26 \\
Tibetan Plateau index & $-0.68^{* * *}$ & $-0.67^{* * *}$ & $-0.53^{* * *}$ & $-0.73^{* * *}$ & $-0.48^{* *}$ \\
\hline
\end{tabular}

515 Note: $* * *$ means $\mathrm{P}<0.01$, ** means $\mathrm{P}<0.05$ and * means $\mathrm{P}<0.1$

516 